\title{
Immediate effect of manual therapy on respiratory functions and inspiratory muscle strength in patients with COPD
}

This article was published in the following Dove Press journal:

International Journal of COPD

20 June 2016

Number of times this article has been viewed

\author{
Gul Deniz Yilmaz Yelvar' \\ Yasemin Çirak ${ }^{2}$ \\ Yasemin Parlak Demir ${ }^{3}$ \\ Murat Dalkilinç' \\ Bülent Bozkurt ${ }^{4}$ \\ 'Department of Musculoskeletal \\ Physiotherapy, ${ }^{2}$ Department of \\ Cardiopulmonary Physiotherapy, \\ ${ }^{3}$ Department of Neurological \\ Rehabilitation, School of \\ Physiotherapy and Rehabilitation, \\ ${ }^{4}$ Department of Respiratory Medicine, \\ Faculty of Medicine, Turgut Özal \\ University, Ankara, Turkey
}

Objective: The objective of this study was to investigate the immediate effect of manual therapy (MT) on respiratory functions and inspiratory muscle strength in patients with COPD.

Participants and methods: Thirty patients with severe COPD (eight females and 22 males; mean age $62.4 \pm 6.8$ years) referred to pulmonary physiotherapy were included in this study. The patients participated in a single session of MT to measure the short-term effects. The lung function was measured using a portable spirometer. An electronic pressure transducer was used to measure respiratory muscle strength. Heart rate, breathing frequency, and oxygen saturation were measured with a pulse oximeter. For fatigue and dyspnea perception, the modified Borg rating of perceived exertion scale was used. All measurements were taken before and immediately after the first MT session. The ease-of-breathing visual analog scale was used for rating patients' symptoms subjectively during the MT session.

Results: There was a significant improvement in the forced expiratory volume in the first second, forced vital capacity, and vital capacity values $(P<0.05)$. The maximal inspiratory pressure and maximal expiratory pressure values increased significantly after MT, compared to the pre-MT session $(P<0.05)$. There was a significant decrease in heart rate, respiratory rate $(P<0.05)$, and dyspnea and fatigue perception $(P<0.05)$.

Conclusion: A single MT session immediately improved pulmonary function, inspiratory muscle strength, and oxygen saturation and reduced dyspnea, fatigue, and heart and respiratory rates in patients with severe COPD. MT should be added to pulmonary rehabilitation treatment as a new alternative that is fast acting and motivating in patients with COPD.

Keywords: manual therapy, COPD, inspiratory muscle strength, pulmonary function dyspnea, fatigue

\section{Introduction}

COPD, which decreases the quality of life and increases the risk of early mortality, is a chronic, preventable, and treatable disease. Although the pulmonary system is affected, COPD has a high frequency of extrapulmonary comorbidities that affect cardiovascular and musculoskeletal systems and can lead to malnutrition. ${ }^{1}$ Structural differences in rib cage configuration, forward head posture, shoulder protraction, ${ }^{2,3}$ reduced bone mineral density, and an increased prevalence of vertebral deformities ${ }^{4}$ have also been reported in COPD.

In COPD patients, the length of the inspiratory muscle fibers is shorter due to hyperinflation. Exposure to oxidative stress and local activation of proteases may also result in inspiratory muscle dysfunction. ${ }^{5}$ Chest wall mechanics are changed and chest wall rigidity occurs in COPD. Hyperinflation and respiratory muscle fatigue produce
Correspondence: Gul Deniz Yilmaz Yelvar School of Physiotherapy and Rehabilitation, Turgut Özal University, Yunus Emre Mahallesi, Takdir Caddesi, No 5 Yenimahalle, Ankara, Turkey Tel +90 3I2 3278250 ext 7203 Email guldenizy@yahoo.com 
hypertonicity in respiratory muscles as well as hypomobility of spinal, costal, and sternal joints that comprise the chest wall. The change in chest wall mechanics may be a factor that causes exercise-limiting dyspnea in COPD. ${ }^{6}$

A decrease in thoracic spine mobility is correlated with a decrease in forced vital capacity (FVC) and forced expiratory volume in the first second $\left(\mathrm{FEV}_{1}\right)$. An increase in chest wall rigidity affects the ventilatory pumping mechanism, reducing the level of rigidity (increasing chest wall mobility), and has been suggested as a way to improve lung function. ${ }^{7-9}$

A previous study on patients with COPD has demonstrated that manual therapy (MT) exercises increase lung function in the short term. ${ }^{10}$ Another study showed that osteopathic manipulative treatment yielded a statistically significant decrease immediately in forced expiratory flow at $25 \%$ and $50 \%$ of vital capacity (VC) and airway resistance in elderly patients. ${ }^{11}$ To the best of our knowledge, there is no study that investigated the immediate effect of MT on inspiratory muscle strength and patient satisfaction in patients with COPD. The hypothesis underlying this study was that MT that includes both soft tissue and joint mobilization immediately increases pulmonary function, inspiratory muscle strength, and patient satisfaction, and decreases dyspnea perception in patients with COPD.

\section{Participants and methods}

The study was conducted in an outpatient office setting and was a collaborative effort between the Department of Respiratory Medicine and the Department of Musculoskeletal Physiotherapy at Turgut Özal University. The study was approved by the ethics committee at Turgut Özal University, Ankara, Turkey. Signed, informed consent forms were obtained from each patient before the study. The inclusion criterion was an $\mathrm{FEV}_{1} / \mathrm{FVC}$ ratio of $\leq 50 \%$ of the predicted value after bronchodilator drugs. The potential subjects were considered if they had a known history of COPD and an office pulmonary function screening. Diagnosis of disease and classification of disease severity were established in line with the Global Initiative for Chronic Obstructive Lung Disease criteria. $^{12}$ The exclusion criteria were as follows: having unstable medical condition, acute bronchitis, pneumonia, an exacerbation of COPD, thoracic spinal scoliosis, substantial chest wall deformity, or acute rib or vertebral fracture. The subjects were excluded if they were unable to perform the pulmonary function test because of cognitive or physical impairments.

The lung function test was performed in a seated position using a portable spirometer (Spirobank; MIR, Rome, Italy) according to the American Thoracic Society guidelines. ${ }^{13}$ Dynamic volumes, including $\mathrm{FEV}_{1}, \mathrm{FVC}$, and VC, were recorded before and after the MT session. All subjects rested before the pulmonary function test to avoid fatigue.

Respiratory muscle strength, maximal inspiratory pressure (MIP), and maximal expiratory pressure (MEP) were assessed using an electronic pressure transducer (MicroRPM; Micro Medical Ltd., Kent, UK). MIP was measured at residual volume, and MEP was measured from total lung capacity, according to Black and Hyatt. ${ }^{14,15}$

The patient's heart rate, breathing frequency, and oxygen saturation were monitored with the pulse oximeter, and the values were recorded before and after the MT session.

Fatigue and dyspnea perception were assessed using the modified Borg rating of perceived exertion scale scores before and after the MT session.

The patients rated their symptoms subjectively during the MT session using the ease-of-breathing visual analog scale (Figure 1). ${ }^{16}$

The same physiotherapist evaluated patients before and immediately after the treatment.

\section{Directions: draw a vertical mark across the horizontal line below to indicate how your breathing feels at this moment.}

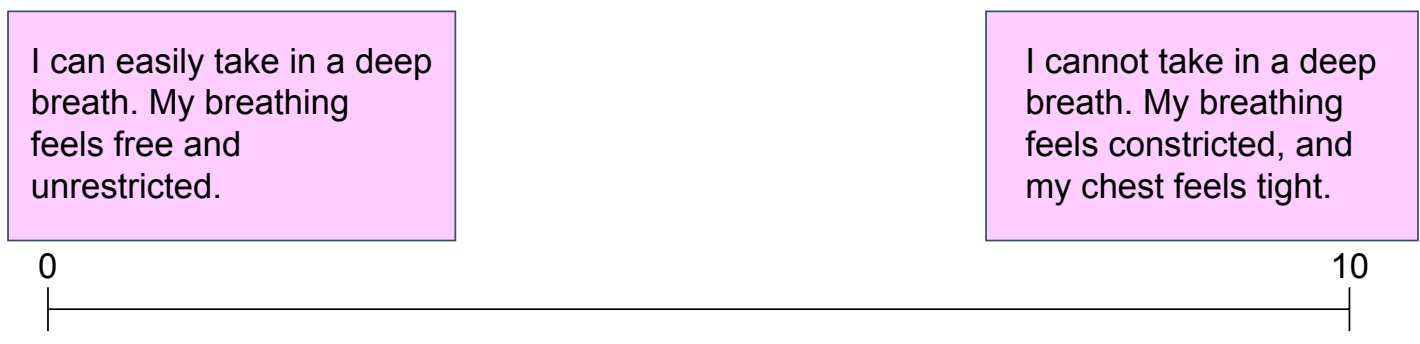

Figure I Ease-of-breathing VAS $(10 \mathrm{~cm})$. Abbreviation: VAS, visual analog scale. 


\section{Manual treatment protocol}

All subjects continued their COPD medications until the day of participation in the study. The MT protocol session lasted $\sim 45$ minutes and consisted of the following MT techniques: suboccipital decompression, ${ }^{11}$ gliding of the cervical vertebral articulations in the anterior/posterior direction, myofascial release of sternocleidomastoid and trapezius muscles, gliding of sternoclavicular joint in the anterior/posterior direction, myofascial release of intercostal muscles and paravertebral muscles, ${ }^{14}$ diaphragmatic release,${ }^{11}$ rib raising, ${ }^{11}$ mobilization of scapulothoracic joint, and gliding of the thoracic vertebral articulations in the anterior/posterior direction. The myofascial release techniques were applied, each for $\sim 3-5$ minutes. The gliding techniques were performed for 30 seconds and five times in each joint.

The MT session was well tolerated without patient complaints, and no adverse effects occurred during the MT session and during evaluation.

A phone survey was administered to account for possible adverse effects occurring within 24 hours. None were reported. Following the MT session, the patients were given a chance to describe their thoughts using the 4-point Likert scale (strongly disagree, disagree, agree, strongly agree).

Statistical analyses were performed using SPSS 16.0 statistical package (SPSS Inc., Chicago, IL, USA). The Kolmogorov-Smirnov/Shapiro-Wilk test was used to analyze normally distributed continuous variables. The descriptive statistics was expressed as mean \pm standard deviation for the continuous variables and in terms of the number of patients and percentage for the categorical variables. Paired $t$-test was performed to compare the results of pre- and posttreatments. $P<0.05$ was considered statistically significant.

\section{Results}

Thirty subjects were enrolled in the study. The mean age of the participants was $62.4 \pm 6.8$ years. Eight of the 30 patients (26.7\%) were females and $22(73.3 \%)$ were males. Demographic and clinical characteristics are shown in Table 1. There was significant improvement in $\mathrm{FEV}_{1}, \mathrm{FVC}$, and VC values $(P<0.05)$. MIP and MEP values increased significantly after MT as compared with the pre-MT session $(P<0.05)$. There was a significant decrease in the heart and respiratory rate $(P<0.05)$. Moreover, there was a significant decrease in dyspnea and fatigue perception $(P<0.05)$. Visual analog scale scores for the patients' breathing significantly improved after MT compared with the pre-MT session $(P<0.05$; Table 2$)$. All patients enjoyed the treatment and
Table I Demographic and clinical characteristics of the subjects

\begin{tabular}{ll}
\hline Characteristics & Mean \pm SD \\
\hline Age, year & $62.4 \pm 6.8$ \\
Male/female, $\mathrm{n}$ & $22 / 8$ \\
Body mass index & $18.7 \pm 2.9$ \\
GOLD III/IV, $\mathrm{n}$ & $26 / 4$ \\
Smoking, pack-years & $46.87 \pm 26.69$ \\
Smoking (nonsmoker/ex-smoker/smoker), $\mathrm{n}(\%)$ & $1 / 27 / 2(3.3 / 90 / 6.7)$ \\
Using oxygen at home, $\mathrm{n}(\%)$ & $20(66.7)$ \\
Medication & \\
$\quad$ Bronchodilators & \\
$\quad$ Inhaled, $\mathrm{n}(\%)$ & $26(86.7)$ \\
$\quad$ Nebulized, $\mathrm{n}(\%)$ & $18(60)$ \\
$\quad$ Ipratropium bromide & \\
$\quad$ Inhaled, $\mathrm{n}(\%)$ & $13(43.3)$ \\
$\quad$ Nebulized, $\mathrm{n}(\%)$ & $\mathrm{II}(36.7)$ \\
Steroids & \\
$\quad$ Inhaled, $\mathrm{n}(\%)$ & $2 \mathrm{I}(70)$ \\
$\quad$ Oral, $\mathrm{n}(\%)$ & $6(20)$ \\
Theophylline, $\mathrm{n}(\%)$ & $8(26.7)$ \\
\hline
\end{tabular}

Abbreviations: SD, standard deviation; GOLD, Global Initiative for Chronic Obstructive Lung Disease.

would recommend it to others. All patients said that they benefited from MT and breathed more easily (Table 3).

\section{Discussion}

This study showed that a single MT session immediately improves pulmonary function, inspiratory muscle strength, and oxygen saturation and reduces dyspnea, fatigue, heart rate, and respiratory rate in patients with COPD.

A previous study, investigating the short-term effect of MT in patients with moderate COPD, administering a soft

Table 2 Results of immediate effects of MT on the pulmonary function, respiratory muscle strength, heart rate, respiratory rate, dyspnea and fatigue perception, and ease of breathing

\begin{tabular}{|c|c|c|c|}
\hline Characteristics & $\begin{array}{l}\text { Pre-MT, } \\
\text { mean } \pm \text { SD }\end{array}$ & $\begin{array}{l}\text { Post-MT, } \\
\text { mean } \pm \text { SD }\end{array}$ & $P$-value \\
\hline $\mathrm{FEV}_{1}, \mathrm{~L}$ & $0.99 \pm 0.4$ & $1.13 \pm 0.4$ & $0.02 *$ \\
\hline FVC, L & $1.96 \pm 0.7$ & $2.05 \pm 0.6$ & $0.04 *$ \\
\hline VC, L & $1.82 \pm 0.4$ & $1.95 \pm 0.7$ & $0.01 *$ \\
\hline MIP, $\mathrm{cmH}_{2} \mathrm{O}$ & $40.27 \pm 16.4$ & $46.18 \pm 19.2$ & $0.03 *$ \\
\hline MEP, $\mathrm{cmH}_{2} \mathrm{O}$ & $99.6 \pm 36.1$ & $120.5 \pm 44.7$ & $0.01 *$ \\
\hline $\mathrm{SpO}_{2}$ & $92.03 \pm 8.2$ & $94.5 \pm 6.9$ & $0.01 *$ \\
\hline Heart rate (beats/min) & $83.4 \pm 12.6$ & $75.8 \pm 17.4$ & $0.01 *$ \\
\hline Respiratory rate & $24.8 \pm 8.3$ & $20.1 \pm 7.6$ & $0.03 *$ \\
\hline Dyspnea (Borg 0-10) & $2.3 \pm 0.8$ & $1.8 \pm 0.5$ & $0.01 *$ \\
\hline Fatigue (Borg 0-10) & $3.1 \pm 0.7$ & $2.4 \pm 0.6$ & $0.01 *$ \\
\hline Ease-of-breathing VAS & $7.8 \pm 2.3$ & $2.4 \pm 1.6$ & $0.00 *$ \\
\hline
\end{tabular}

Note: $* P<0.05$.

Abbreviations: MT, manual therapy; SD, standard deviation; FEV, forced expiratory volume in the first second; FVC, forced vital capacity; VC, vital capacity; MIP, maximal inspiratory pressure; MEP, maximal expiratory pressure; min, minute; $\mathrm{SpO}_{2}$, oxygen saturation; VAS, visual analog scale. 
Table 3 Patients' thoughts about the treatment

\begin{tabular}{|c|c|c|c|c|}
\hline & $\begin{array}{l}\text { Strongly disagree } \\
\text { n (\%) }\end{array}$ & $\begin{array}{l}\text { Disagree } \\
\mathrm{n}(\%)\end{array}$ & $\begin{array}{l}\text { Agree } \\
\text { n (\%) }\end{array}$ & $\begin{array}{l}\text { Strongly agree } \\
\text { n (\%) }\end{array}$ \\
\hline I benefited from the treatment & & & $5(17)$ & $25(83)$ \\
\hline I breathed more easily after the treatment & & & $2(7)$ & $28(93)$ \\
\hline I enjoyed receiving the treatment & & & & $30(100)$ \\
\hline I would recommend the treatment to other patients with COPD & & & & $30(100)$ \\
\hline
\end{tabular}

tissue-based form of MT did not produce any short-term improvements in lung function, dyspnea levels, or exercise performance. ${ }^{10}$ Combining this with a joint-based form of MT improved the dyspnea levels in the short term. ${ }^{10}$ According to the study results, a single MT session of soft tissue and joint mobilization immediately improved dyspnea. The authors previously reported that MT increases respiratory muscle length and thoracic cage flexibility. These effects reduce the effort of breathing and development of dyspnea in COPD. ${ }^{17}$

Noll et al ${ }^{11}$ reported that one-session osteopathic manual treatment was effective in improving static and dynamic pulmonary function in elderly patients with COPD. Similarly, in our study, the difference between dynamic pulmonary function parameters and baseline to posttreatment was found to be statistically significant. MT techniques improve the regulation of the autonomic nervous system. Mobilization of the sympathetic system region may cause inhibition of the sympathetic activation, and diaphragmatic release may cause activation of the parasympathetic system. The autonomic system regulates relaxation; therefore, it reduces dyspnea, fatigue, and rate of respiration and increases pulmonary function and oxygen saturation. ${ }^{16}$

The results showed that MT had immediate effect on inspiratory muscle strength in patients with COPD. COPD is both restrictive and obstructive in nature. The patients with COPD tend to have a flexor posture in the upper quarter and to breathe using upper chest muscles. These changes cause excessive activation of the accessory respiratory muscles. ${ }^{18}$ de Andrade et $\mathrm{al}^{19}$ reported in their study that activation of the sternocleidomastoid muscle was negatively correlated with the level of obstruction in the elderly patients with $\mathrm{FEV}_{1} 45 \% \pm 17 \%$.

We think that MT techniques provide relaxation, an increase in thoracic region mobility, and chest wall compliance. Thoracic cage flexibility and muscle relaxation reduce breathing effort and increase muscle function.

The patients reported satisfaction with MT treatment and would recommend it to others. All patients said that they benefited from MT and breathed more easily after a single session.
Several limitations should be considered when interpreting the study results. Although the results were statistically significant when compared with the pretreatment and posttreatment outcomes, the main limitations are the lack of the sham group and the presence of static volume measurements as the effect of MT on hyperinflation. Future studies should focus on mild-to-moderate COPD patients, the effect of MT on different levels of COPD, and the long-term effect of MT. In addition, lung residual volume and total lung capacity should be evaluated to clarify the effect of MT on dynamic hyperinflation.

\section{Conclusion}

The nature of the conditions, symptoms, and functional limitations vary among patients; therefore, the management of COPD is complex. This is the first study to investigate the immediate effect of MT on inspiratory muscle strength and patient satisfaction in patients with COPD. MT should be integrated with pulmonary rehabilitation as a new alternative that produces fast results while motivating patients to continue treatment.

\section{Disclosure}

The authors report no conflicts of interest in this work.

\section{References}

1. Cavailles A, Brinchault-Rabin G, Dixmier A, et al. Comorbidities of COPD. Eur Respir Rev. 2013;22(130):454-475.

2. Kasai T, Yamada M, Narushima M, Suzuki H. Relationship between thoracic cross-sectional area measured on $\mathrm{CT}$ and pulmonary function or dyspnea in patients with COPD. Nihon Kokyuki Gakkai Zasshi. 2003; 41(8):526-530.

3. Walsh JM, Webber CL Jr, Fahey PJ, Sharp JT. Structural change of the thorax in chronic obstructive pulmonary disease. J Appl Physiol (1985). 1992;72(4):1270-1278.

4. Kjensli A, Falch JA, Ryg M, et al. High prevalence of vertebral deformities in COPD patients: relationship to disease severity. Eur Respir J. 2009;33(5):1018-1024.

5. Papandrinopoulou D, Tzouda V, Tsoukalas G. Lung compliance and chronic obstructive pulmonary disease. Pulm Med. 2012;2012: 542769.

6. O'Donnell DE, Laveneziana P. Dyspnea and activity limitation in COPD: mechanical factors. COPD. 2007;4(3):225-236.

7. Aliverti A, Kayser B, Macklem PT. A human model of the pathophysiology of chronic obstructive pulmonary disease. Respirology. 2007;12(4): 478-485. 
8. Mellin G, Harjula R. Lung function in relation to thoracic spinal mobility and kyphosis. Scand J Rehabil Med. 1987;19(2):89-92.

9. Pepin V, Saey D, Laviolette L, Maltais F. Exercise capacity in chronic obstructive pulmonary disease: mechanisms of limitation. COPD. 2007; 4(3):195-204.

10. Engel RM, Vemulpad SR, Beath K. Short-term effects of a course of manual therapy and exercise in people with moderate chronic obstructive pulmonary disease: a preliminary clinical trial. J Manipulative Physiol Ther. 2013;36(8):490-496.

11. Noll DR, Degenhardt BF, Johnson JC, Burt SA. Immediate effects of osteopathic manipulative treatment in elderly patients with chronic obstructive pulmonary disease. $J$ Am Osteopath Assoc. 2008;108(5): 251-259.

12. Global Strategy for the Diagnosis, Management and Prevention of COPD, Global Initiative for Chronic Obstructive Lung Disease (GOLD). 2015. Available from: http://goldcopd.org/global-strategy-diagnosismanagement-prevention-copd-2016. Accessed May 11, 2016.

13. Lung function testing: selection of reference values and interpretative strategies. American Thoracic Society. Am Rev Respir Dis. 1991;144(5): 1202-1218.
14. American Thoracic Society/European Respiratory Society. ATS/ERS Statement on respiratory muscle testing. Am J Respir Crit Care Med. 2002;166(4):518-624

15. Black LF, Hyatt RE. Maximal respiratory pressures: normal values and relationship to age and sex. Am Rev Respir Dis. 1969;99(5):696-702.

16. Bockenhauer SE, Julliard KN, Lo KS, Huang E, Sheth AM. Quantifiable effects of osteopathic manipulative techniques on patients with chronic asthma. J Am Osteopath Assoc. 2002;102(7):371-375. Discussion 375.

17. Engel R, Vemulpad S. The role of spinal manipulation, soft-tissue therapy, and exercise in chronic obstructive pulmonary disease: a review of the literature and proposal of an anatomical explanation. $J$ Altern Complement Med. 2011;17(9):797-801.

18. Chaitow L, Bradley D, Gilbert C. Multidisciplinary Approaches to Breathing Pattern Disorders. London: Churchill Livingstone; 2002.

19. de Andrade AD, Silva TN, Vasconcelos H, et al. Inspiratory muscular activation during threshold therapy in elderly healthy and patients with COPD. J Electromyogr Kinesiol. 2005;15(6):631-639.
International Journal of COPD

\section{Publish your work in this journal}

The International Journal of COPD is an international, peer-reviewed journal of therapeutics and pharmacology focusing on concise rapid reporting of clinical studies and reviews in COPD. Special focus is given to the pathophysiological processes underlying the disease, intervention programs, patient focused education, and self management protocols.

\section{Dovepress}

This journal is indexed on PubMed Central, MedLine and CAS. The manuscript management system is completely online and includes a very quick and fair peer-review system, which is all easy to use. Visit http://www.dovepress.com/testimonials.php to read real quotes from published authors.

Submit your manuscript here: http://www.dovepress.com/international-journal-of-chronic-obstructive-pulmonary-disease-journal 